\title{
PERIARTERITIS NODOSA AND SUBPERIOSTEAL NEW BONE FORMATION
}

\author{
K. A. E. MEIJERS, D. M. PARÉ, H. LOOSE, F. EULDERINK, D. R. SIEWERTSZ VAN REESEMA
}

From University Hospital, Leyden

\begin{abstract}
Three cases of periarteritis nodosa are reported with subperiosteal new bone formation. Two patients have been followed for over five years, the third for only six months. The vascular changes were predominantly found in the smaller vessels, the necrosis and elastin destruction was less than that usually found at necropsy. The radiological follow-up of one case demonstrated ossification and healing of the periosteal changes.
\end{abstract}

In 1956 Saville noted an association between periarteritis nodosa and subperiosteal new bone formation. Since then 13 further cases have been reported (Lovell and Scott 1956; Serre, Simon and Mion 1961 ; Ball and Grayzel 1964; Murray and Jacobson 1971; Tonge 1972; Woodward and Andreini 1974; Brandrup, Petersen and Hansen 1980). These 13 patients were aged 30 to 70 years, and 12 were men.

Although periarteritis nodosa is usually considered to be a disseminated inflammatory vascular disease, in these published cases the involved vessels were found only in the skin, muscles, periosteum and nerves of the affected extremities (Woodward and Andreini 1974; Brandrup et al. 1980). The clinical picture is characterised by deep pain with swelling and purple mottling of the skin, with or without nodules and ulcers.

We present a further three patients: two men whose symptoms began in their second and third decades, and an elderly woman.

\section{CASE REPORTS}

Case 1. A 23-year-old man first noticed a swelling of his right knee in 1968 which then became painful. His erythrocyte sedimentation rate (ESR) was 30 millimetres in the first hour and the latex-fixation test was negative. Radiographs of the right knee showed no abnormality, although retrospective examination showed a small periosteal line to be visible on the distal femur. A synovial biopsy, followed by a synovectomy, was performed and the histological findings were thought to be compatible with rheumatoid arthritis. Both the synovial tissue and fluid were sterile on culture.

The knee gradually deteriorated until he had to give up his job as a truckdriver, and in September 1979 he was seen by an orthopaedic surgeon because of increasing pain and swelling of the thigh and very limited function of the knee. The ESR was now 58 millimetres. A dense apposition of periosteal new bone of the right femoral shaft and proximal shaft of the tibia and fibula was visible on the radiograph. A biopsy was taken of the femur but the histological examination was inconclusive.

In August 1980 the patient was referred to our hospital. He was in obvious pain and had a grossly thickened right thigh with a circumferential difference of 12 centimetres at 15 centimetres proximal to the upper margin of the patella (Fig. 1). The skin was mottled and warm but not adherent to the bone. No nodules, ulcers or varices were present. The range of the movement of the right knee was limited ( 30 degrees to 60 degrees).

On physical examination no abnormality could be detected in the heart, lungs, abdomen, or the other joints. Blood pressure was $140 / 90$ millimetres of mercury. There was a mild pyrexia.

Laboratory findings. The ESR was 44 millimetres in the first hour. haemoglobin 8.9 millimoles per litre and alkaline phosphatase 108 Bessey units per litre (normal, 60 units per litre). The leucocyte count was normal. The Venereal Disease Reference Laboratory and Kolmer reactions, Rose-Waaler and latex-fixation tests were all negative and antinuclear factors were absent. There were no signs of a preceding hepatitis $\mathbf{A}$ or $\mathbf{B}$ infection nor of other virus-induced disease, and no proteinuria.

Radiological examination. The distal two-thirds of the femoral shaft were surrounded by dense periosteal new bone with irregular margins and rounded translucent areas (Figs 2 and 3). Similar but milder appearances were present in the tibia and fibula (Fig. 4). The left femur and tibia were normal. The right knee showed changes of degenerative disease. Scans with ${ }^{19} \mathrm{~m}$ Tc-EHDP and gallium-67 citrate showed high activity on the distal part of the right femur and the proximal part of the right tibia. Arteriograms of the superior mesenteric and the right femoral arteries were normal.

Biopsy findings. A biopsy was performed on the medial side of the femur 30 centimetres proximal to the joint space, and the soft tissues were found to be very oedematous, the muscle pale, the periosteum thickened and many small holes were visible on the bone surface. A piece of periosteum and a four-centimetre bone plug were punched out and the medullary canal was entered. The material derived from the marrow contained soft gritty tissue with blood clots. Cultures were negative.

On histological examination the cylinder of newly formed bone and the adjacent original femoral bone consisted of a narrow mesh of coarse trabeculae, in which the original cortical bone could not be

K. A. E. Meijers, Department of Rheumatology

D. M. Paré, Department of Orthopaedic Surgery

H. Loose, Department of Radiology

F. Eulderink, Department of Pathology

D. R. Siewertsz van Reesema, Department of Rheumatology

University Hospital, Rijnsburgerweg 10,2333 AA Leyden, The Netherlands.

Requests for reprints should be sent to Dr K. A. E. Meijers.

(C) 1982 British Editorial Society of Bone and Joint Surgery 0301-620X/82/5091-0592 \$2.00 


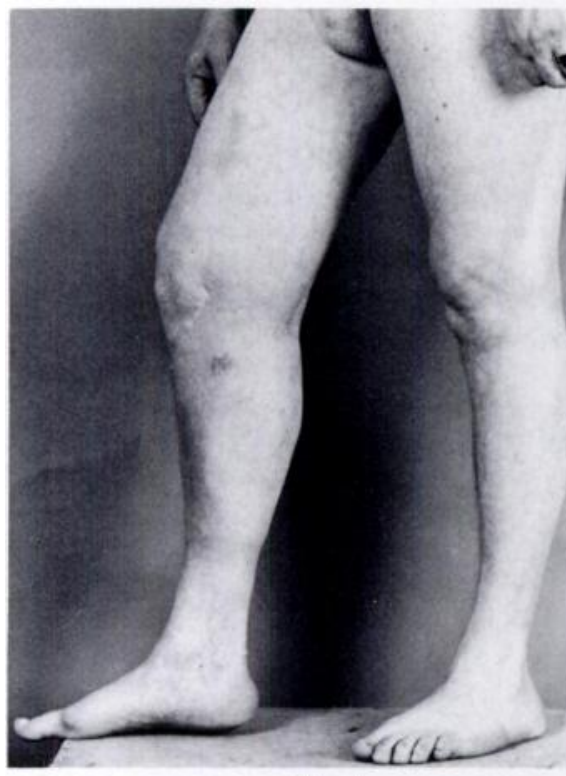

Fig. 1

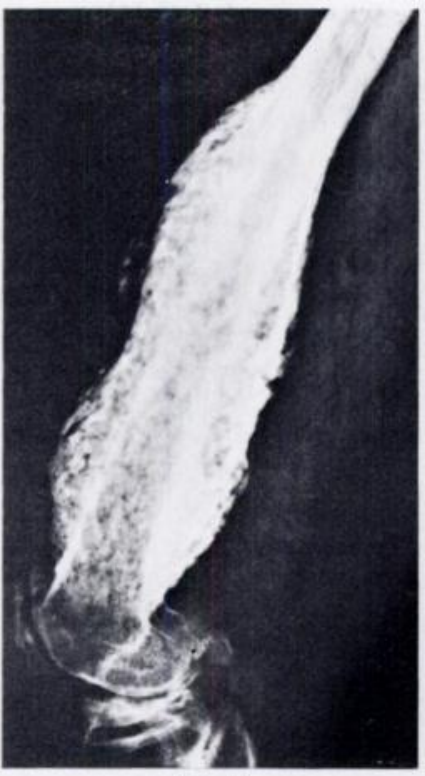

Fig. 2

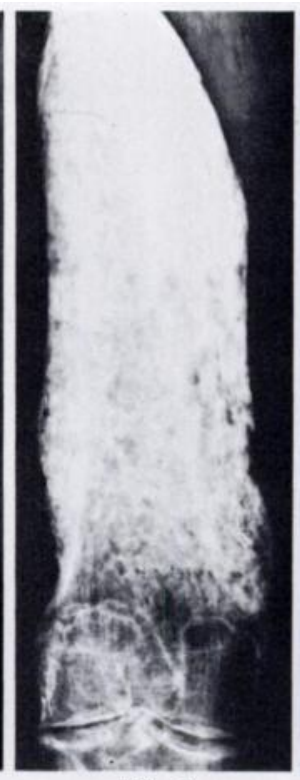

Fig. 3

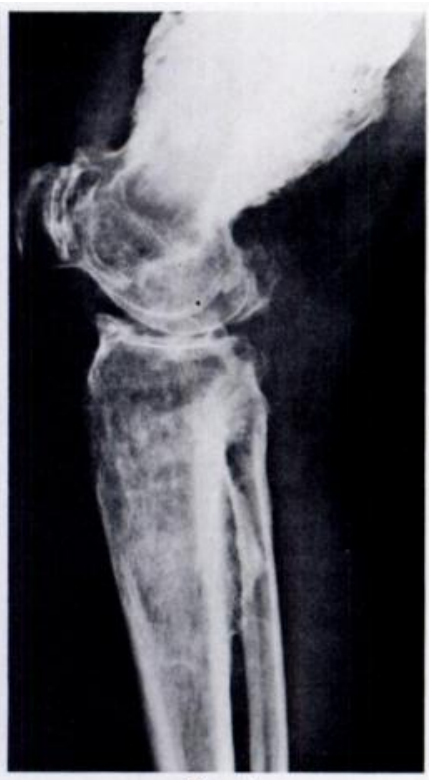

Fig. 4

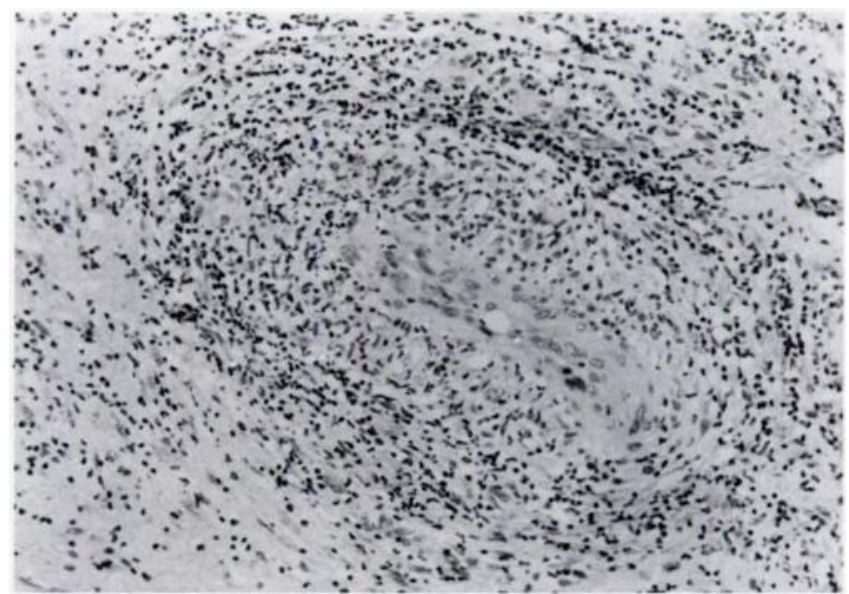

Fig. 5

Case 1. Figure 1-The gross discrepancy in leg thickness. Figures 2 and 3-Lateral and anteroposterior radiographs showing dense hypertrophic new bone formation around the right femur. Figure 4Irregular periosteal new bone formation in the right tibia and to a lesser extent in the right fibula. Figure 5-Small artery or vein, with proliferation of fibroblasts, some oedema of the vessel wall and an infiltration in and around the vessel by neutrophilic granulocytes and some lymphocytes.

distinguished as a separate layer. The marrow spaces between the trabeculae were filled by fat or areolar connective tissue with occasional foci of granulocytes or lymphocytes. In the areas with granulocytes many osteoclasts lined the bony trabeculae whereas in other areas osteoblastic activity was seen. The thickened periosteum appeared to merge gradually with fibrous tissue that contained scattered striated muscle fibres and fat. Lesions were found in both small arteries and veins, occasionally affecting only a segment of the vessel. These lesions consisted of intimal proliferation of fibroblasts, some oedema of the vessel wall and a variable infiltration in and around the vessel by neutrophilic and eosinophilic granulocytes and some lymphocytes. All these three factors contributed to the narrowing of the lumen (Fig. 5). Occasional small foci of fibrinoid necrosis of the tunica media or destruction of the elastic membrane were found.

The patient was treated with 30 milligrams of prednisone and 150 milligrams of azathioprine daily. After three months he was feeling well, the leg was painless, less swollen, and not tender. The ESR was normal.
Case 2. A 76-year-old woman noticed a swelling behind her right knee in February 1974. In the following months the lower leg became red, swollen, painful and warm, and in July 1974 she was admitted with a pyrexia. On examination the heart, lungs and the abdomen were normal, and the blood pressure varied between $180 / 110$ and 170/100 millimetres of mercury. The skin showed no abnormalities.

Laboratory findings. The ESR was 42 and 85 millimetres in the first and second hour and serum alkaline phosphatase level was raised to 108 Bessey units per litre; serum creatinine, serum urea and the leucocyte count were normal. Rose-Waaler and latex-fixation tests were negative and antinuclear factors were absent. Urine analysis showed no abnormalities.

Radiological examination. The right tibia and fibula showed periosteal cuffing around the mid shaft (Fig. 6).

Biopsy findings. On surgical exploration the swelling was found to be within the proximal part of the gastrocnemius muscle. Biopsies were taken from this as well as from the tibia. No organisms were seen on microscopic examination and the cultures remained sterile. The biopsy 


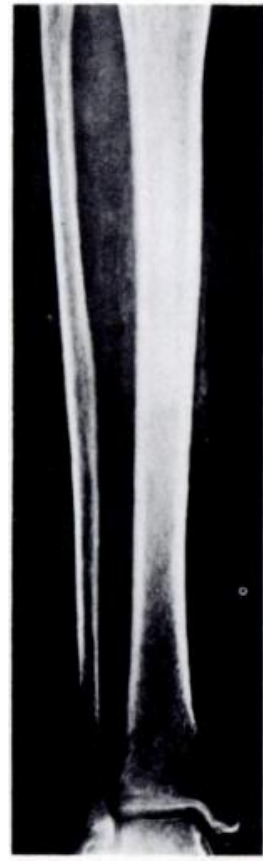

Fig. 6

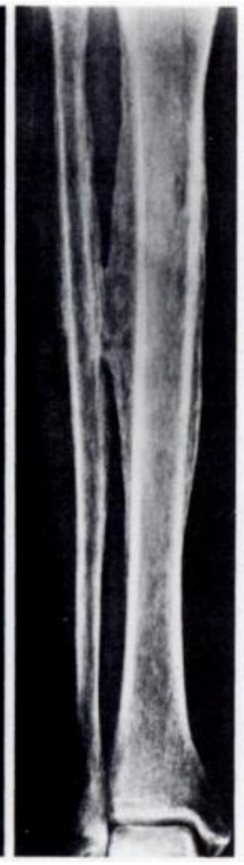

Fig. 7
Case 2. Figure 6-Periosteal cuffing around the mid-shaft of tibia and fibula. Figure 7-Ossification of the periosteal reaction six years after presentation.

from the node in the gastrocnemius muscle showed striated muscle with interstitial fibrosis, oedema, focal infiltration by lymphocytes and occasional neutrophilic and eosinophilic granulocytes. Small vessels, mainly arterioles, were affected by proliferative changes and infiltration by granulocytes (including several eosinophils), occasionally leading to obliteration of the lumen. Fibrinoid necrosis was visible in only one arteriole, and in some places there was destruction of the elastic membrane. Atrophy, degenerative and regenerative changes with giant cells were found in the striated muscle. probably secondary to the proliferative and exudative vasculitis. There were no signs of systemic vasculitis.

Treatment was started with 15 milligrams of prednisone and 100 milligrams of azathioprine daily. The swelling at the back of the knee subsided quickly and the redness and pain in the lower leg more gradually. The patient has been free of pain since 1977 when all medications were withdrawn. The ESR fell to normal as soon as the treatment was started and remained unchanged.

The radiograph taken in 1980 showed ossification of the subperiosteal reaction (Fig. 7).

Case 3. Since 1961 a 28 -year-old Indonesian man had suffered from short attacks of pain, redness and swelling of both ankles which recurred every three to six months. Since 1964 he had also noticed small black dots on his skin, lasting for a few days.

In October 1975 he was treated elsewhere with high doses of prednisone daily, but the attacks of pain and swelling did not regress. Concurrently, he noticed tingling and numbness of both feet and the skin became ulcerated. There was mild proteinuria with a few leucocytes and erythrocytes in the sediment, though the creatinine clearance test was normal. He was referred to the University Hospital in December 1975. On examination he looked ill and very depressed and was completely bedridden. His rectal temperature was 38.3 degrees Celsius. Blood pressure was 110/70 millimetres of mercury and no abnormalities were found on physical examination of the heart and lungs. The liver and spleen were not palpable, but both testes and epididymides were enlarged with an irregular consistency. The muscles of the lower legs were atrophied with mottled skin and the ankles and the dorsum of the feet were swollen. Necrotic areas and ulcers were found over both medial malleoli, on the plantar and dorsal side of the feet, and on the fourth and fifth toes of the left foot. There was a loss of sensibility on the lower legs and feet, and movements of the ankle joints and toes were very restricted.

Laboratory findings. The ESR was 150 millimetres in the first hour, haemoglobin 5.4 millimoles per litre and the leucocyte count was raised to $13.3 \times 10^{4}$ per litre; serum creatinine level was normal. Proteinuria was less than one gram in 24 hours but there was sediment in the urine comprising a few leucocytes and erythrocytes. Blood and urine cultures were negative. Antinuclear factor, serological tests for Australia antigen, Rose-Waaler and latex-fixation tests were negative. The complement profile was normal, the direct Coombs' test was negative and cryoglobulins were absent. The serum analysis showed that, per litre, alkaline phosphatase was raised to 420 units, the 5-nucleotidase to 72.2 units (normal is 10.5 units), glutamic oxaloacetic transaminase to 27 units and glutamic pyruvic transaminase to 50 units (both normals are 15 units): lactic dehydrogenase was below normal at 126 units. Serum bilirubin, total serum protein and albumin were normal.

Radiological examination. On an intravenous pyelogram the left kidney was shown to be non-functional, while the right kidney was normal. A repeat examination six weeks later showed the right kidney to be enlarged with congested fornices and calices, and the right ureter displaced medially with multiple narrowed areas. A renal and abdominal arteriogram showed a hypoplastic left renal artery with impaired vascularisation of the left kidney. Radiographs of both tibiae and fibulae showed periosteal new bone formation throughout the shaft (Fig. 8).

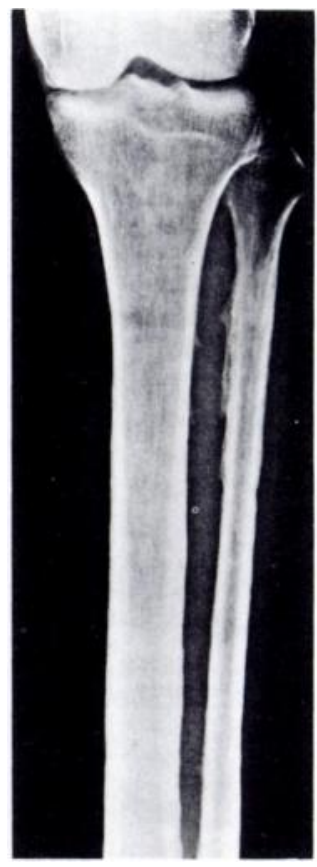

Fig. 8

Case 3. Periosteal new bone formation along the tibia and fibula.

Histological examination. The left testicle, removed for diagnostic reasons, was surrounded by a thickened tunica albuginea (up to nine millimetres thick). Several small and medium sized arteries in the capsule, epididymis, funiculus spermaticus and focally within the testicle showed proliferation of fibroblasts and infiltration of the vessel wall by lymphocytes, histiocytes and eosinophils leading to narrowing or obliteration of the lumen. There were areas of focal fibrinoid necrosis of the vessel wall, interruption of the elastic membrane and thrombosis. The testicle showed secondary changes of necrosis or fibrosis. Inflamed vessels in the retroperitoneal fat were considered to be the cause of the pyelographic changes. The patient was treated with 45 milligrams of 
prednisone daily. Six weeks later he was feeling well and his depression had subsided. Although the numbness of his feet was still present he was able to walk. Intravenous pyelograms made two and four weeks after prednisone treatment was started showed a progressive reduction in the size of the right kidney to normal and the return of function to the left kidney. The skin improved and the ulcers healed, but the fourth and fifth toe had become necrotic and were amputated later. Liver function tests returned to normal and the ESR fell from 130 to 25 millimetres.

Five years later, the patient had short-lasting pains in the right lower leg and had small ulcers on the right foot. The numbness had subsided and he was able to work. The new bone formation was still present. Features of a systemic vasculitis were no longer present. Liver and renal function tests were normal.

\section{DISCUSSION}

Generalised periarteritis nodosa is not a rare disease and may occur in all age groups with predominance in middle age. It is commoner in men than in women. The complication of subperiosteal new bone formation is rare and is found predominantly in men. The clinical picture is of deep pain and swelling in the affected limb or limbs, as seen in our patients, and there is great variation in duration of the disease before the diagnosis is made (Table I).

The biopsies all showed vasculitis of small arteries and probably small veins which was mainly proliferative and exudative. Necrosis and destruction of the elastic membrane was not often found. Eosinophils were found in and around the walls of the inflamed vessels. Though the histological picture was quite consistent with periarteritis nodosa, the calibre of affected vessels was somewhat smaller than is usually found in periarteritis nodosa at necropsy. This preference for the smaller vessels may be explained by the poor prognosis of necrotising periarteritis in the larger vessels which in the past has usually proved fatal before any clinical manifestation of periosteal new bone formation.

In the first two cases the vascular changes were localised. In our third patient, however, the lesions were

Table I. Previous reports of periarteritis nodosa and subperiosteal new bone formation

\begin{tabular}{|c|c|c|c|c|c|c|c|}
\hline References & Sex & $\begin{array}{c}\text { Age } \\
\text { (years) }\end{array}$ & $\begin{array}{l}\text { Delay in } \\
\text { diagnosis }\end{array}$ & Site of periostitis & $\begin{array}{l}\text { Site of biopsy } \\
\text { showing PAN }\end{array}$ & Treatment & Follow-up \\
\hline Saville 1956 & $\mathbf{M}$ & 58 & 9 months & $R, L:$ tibia, fibula & $\begin{array}{l}\text { Fibula }+ \text { soft } \\
\text { tissue }\end{array}$ & Cortisone & 1 year: well \\
\hline $\begin{array}{l}\text { Lovell and Scott } \\
1956\end{array}$ & $\mathbf{M}$ & 58 & 2 years & $\begin{array}{l}\mathrm{R}, \mathrm{L}: \text { ulna, radius, } \\
\text { tibia, fibula }\end{array}$ & Skin nodule & Cortisone $100 \mathrm{mg}$ daily & 3 years $\dagger$ \\
\hline \multirow[t]{2}{*}{ Serre et al. 1961} & $\mathbf{M}^{*}$ & 35 & 2 months & $\begin{array}{l}\text { R: tibia, metatarsal } \\
\text { L: fibula }\end{array}$ & Skin, muscle & Triamcinolone & Not noted \\
\hline & $\mathbf{M}$ & 58 & 1 year & $\begin{array}{l}\text { R: tibia } \\
\text { L: fibula }\end{array}$ & $\begin{array}{l}\text { Muscle, } \\
\text { periosteum }\end{array}$ & Cortisone $100 \mathrm{mg}$ & 7 years: still alive \\
\hline \multirow[t]{3}{*}{$\begin{array}{l}\text { Ball and Grayzel } \\
1964\end{array}$} & $\mathbf{M}$ & 36 & 2 years & L: tibia, fibula & Periosteum & Prednisone $20 \mathrm{mg}$ & $\begin{array}{l}1 \text { year: well; relapse } \\
\text { on stopping } \\
\text { prednisone }\end{array}$ \\
\hline & $\mathbf{M}$ & 63 & 3 months & L: tibia & Periosteum & Steroids & $\begin{array}{l}2 \text { years: well: still on } \\
\text { steroids }\end{array}$ \\
\hline & $\mathbf{M}$ & 58 & 2 years & $\begin{array}{l}\text { R,L: tibia, fibula } \\
\text { ? L: femur }\end{array}$ & Muscle & $?$ & $?$ \\
\hline Tonge 1972 & F & 31 & 6 months & $\begin{array}{l}\mathrm{R}, \mathrm{L}: \text { ulna, radius, } \\
\text { metacarpals, tibia, } \\
\text { metatarsals }\end{array}$ & Skin nodule & Prednisone $20-10 \mathrm{mg}$ & $\begin{array}{l}7 \text { years: well: still on } \\
\text { prednisone }\end{array}$ \\
\hline $\begin{array}{l}\text { Murray and } \\
\text { Jacobson } 1971\end{array}$ & $\mathbf{M}$ & 70 & 6 years & ? tibia, fibula & $?$ & $?$ & $?$ \\
\hline \multirow[t]{3}{*}{$\begin{array}{l}\text { Woodward and } \\
\text { Andreini } 1974\end{array}$} & $\mathbf{M}$ & 46 & 7 years & $\begin{array}{l}\mathrm{R}, \mathrm{L}: \text { tibia, fibula } \\
\mathrm{L}: \text { metatarsal }\end{array}$ & Skin nodule & Prednisone & Not noted \\
\hline & $\mathbf{M}$ & 53 & 6-9 months & L: tibia & Skin nodule & Prednisone & $\begin{array}{l}1 \text { year: well; still on } \\
\text { prednisone }\end{array}$ \\
\hline & $\mathbf{M}$ & 59 & 3 months & R,L: tibia, fibula & Skin & No therapy & No follow-up \\
\hline $\begin{array}{l}\text { Our patients } 1982 \\
\text { Case 1 }\end{array}$ & $\mathbf{M}$ & 35 & 12 years & $\begin{array}{l}\text { R: femur, tibia, } \\
\text { fibula }\end{array}$ & Periosteum & $\begin{array}{l}\text { Prednisone } 30 \mathrm{mg} \\
\text { Azathioprine } 150 \mathrm{mg}\end{array}$ & $\begin{array}{l}6 \text { months: well: still } \\
\text { on therapy }\end{array}$ \\
\hline Case 2 & $\mathrm{~F}$ & 76 & 6 months & R: tibia, fibula & Muscle & $\begin{array}{l}\text { Prednisone } 15 \mathrm{mg} \\
\text { Azathioprine } 100 \mathrm{mg}\end{array}$ & $\begin{array}{l}6 \text { years: well: therapy } \\
\text { stopped after } 3 \text { years }\end{array}$ \\
\hline Case $3^{*}$ & $\mathbf{M}$ & 28 & 14 years & $\mathrm{R}, \mathrm{L}:$ tibia, fibula & Testis & Prednisone $45 \mathrm{mg}$ & $\begin{array}{l}5 \text { years: well: still on } \\
\text { prednisone }\end{array}$ \\
\hline
\end{tabular}

* Generalised periarteritis nodosa

† Died of pulmonary embolism; at necropsy vascular lesions were absent in internal organs. 
more generalised at the time of admission in 1975, but at follow-up five years later seemed to be limited to the right leg. The periostitis present in the extremities had a predilection for tibia and fibula (Saville 1956; Ball and Grayzel 1964; Murray and Jacobson 1971; Woodward and Andreini 1974; Brandrup et al. 1980; Table I).

Radiologically the periostitis usually has the appearance of a smooth layer added to the existing bone. The gross undulating periosteal bone reaction around the femur, and to a lesser extent around the tibia and fibula in Case 1, is quite exceptional. Murray and Jacobson (1971) reported a tibia with similar ragged outgrowth, but more details about this patient are lacking. It seems very likely that this particular picture is the result of a longstanding vascular disease, which pursued a chronic untreated course for a period of 12 years, as indeed a small periosteal line was already visible on the femur of the right knee in 1968. In the second patient the periostitis had a smooth appearance and occurred after a relatively short period of about six months. At follow-up six years later it was still present, but had filled in with new bone and appeared inactive. We do not expect any further regression of the radiological changes.

Diaphysial periosteal new bone formation is not specific and is seen in all forms of hypertrophic osteoarthropathy, trauma, in combination with varicose ulceration, osteomyelitis and juxtacortical osteosarcoma. Initially our first two patients were considered to be suffering from a chronic osteomyelitis and were treated as such. A similar course is also recorded in three cases in the literature (Serre et al. 1961; Ball and Grayzel 1964; Woodward and Andreini 1974). When the diagnosis of periarteritis nodosa became apparent, we considered the new bone formation to be a reaction to the vascular inflammatory changes.

The aetiology of periarteritis nodosa is still unknown. Immunological processes undoubtedly play an important role, but other factors such as repeated trauma cannot be excluded. In the literature most patients with localised periarteritis nodosa with new bone formation were treated with corticosteroids (Table I), with a variable follow-up of up to seven years. Our first two patients were treated with prednisone and azathioprine while the third patient was treated with prednisone only. All three responded favourably in that the pain subsided and the temperature and the sedimentation rate returned to normal.

The follow-up period of the first patient is only six months. The second patient has been followed for six years, three years being without therapy, and there has been no recurrence of symptoms. The third patient has been followed for five years and is still on low doses of corticosteroids; his only complaints are of occasional pains in his right lower leg together with small ulcers.

In all patients with pain, skin changes and swelling of one or more extremities, the diagnosis of localised periarteritis nodosa with periostitis has to be considered, as they can be effectively treated.

\section{REFERENCES}

Ball J, Grayzel AI. Arteritis and localised periosteal new bone formation. J Bone Joint Surg [Br] 1964:46-B:244-50.

Brandrup F, Petersen EM, Hansen BF. Localized polyarteritis nodosa in the lower limb with new bone formation. Acta Derm Venereol (Stockh) $1980 ; 60: 182-4$.

Lovell RRH, Scott GBD. Hypertrophic osteo-arthropathy in polyarteritis. Ann Rheum Dis 1956;15:46-50.

Murray RO, Jacobson HG. The radiology of skeletal disorders. Edinburgh and London: Churchill Livingstone, $1971: 2: 451$.

Saville PD. Polyarteritis nodosa with new bone formation. J Bone Joint Surg [Br] 1956:38-B:327-33.

Serre H, Simon L, Mion C. Réaction périostée avec néo-formation osseuse révélatrice d'une périartérite nodeuse. Rev Rhum 1961:28:120-3.

Tonge K. Periosteal reaction in polyarteritis nodosa. Br J Radiol 1972;45:698-700.

Woodward AH, Andreini PH. Periosteal new bone formation in polyarteritis nodosa: a syndrome involving the lower extremities. Arthritis Rheum 1974:17:1017-25. 